\title{
A PROPOSITO DEL WALRAS DE SEGURA
}

\author{
CARLOS RODRIGUEZ BRAUN \\ Universidad Complutense
}

Alianza Editorial ha publicado recientemente la primera versión castellana de los Elementos de economía politica pura, de Walras, en edición y traducción de Julio Segura. Léon Walras (1834-1910) fue un extraordinario economista que coprotagonizó la ya centenaria Revolución Marginal y contribuyó mucho a dar a la ciencia económica rasgos que la caracterizan aún hoy. Además, era reformador progresista, y Julio Segura -en su introducción a los Elementos y en un artículo reciente en la Revista dE Historia Económica- parece creer que la posteridad ha ignorado vergonzante ese color ideológico y ha dado una imagen sesgada de Walras.

\section{Bienvenue, Monsieur Walras}

La única forma de comenzar es felicitar a editor y editorial por la espléndida idea de traducir los Elementos. Se llena así una de las dos mayores lagunas que tenía la literatura económica en castellano sobre las grandes obras de la referida Revolución Marginal, denominación algo ampulosa que recibe la coincidencia de la publicación en la década de 1870 de varios tratados sobre economía que modificaron el enfoque que la misma había tenido virtualmente desde sus orígenes. Con la anterior edición de los Principios, de Menger, por Unión Editorial, y esta flamante de Walras, resta esperar a la Theory of political economy, de Jevons, de la cual, dicho sea de paso pero con severidad, cierta editorial madrileña almacena inexplicablemente una traducción efectuada hace algunos años por Juan Antonio Pérez-Campanero.

En suma, los economistas hispanohablantes están de parabienes con esta ilustre incorporación a la bibliografía, y ante todo cabe decir «Bienvenue, Monsieur Walras». 
Walras, teórico y práctico

Aunque Walras tuvo múltiples inquietudes sociales y dejó importantes trabajos en el campo de la economía «aplicada» y «social», pasó a la posteridad por su labor en el campo de la teoría pura, plasmada principalmente en sus Elementos (1874-77), que por sí solos ciertamente bastan y sobran para colocarlo entre los grandes de la disciplina.

Si los tres protagonistas de la revolución marginalista - Jevons, Menger y Walras- explican el valor de las mercancías a través de la utilidad y no a través del coste como era lo habitual, Walras aporta, además, la primera visión de la economía en un esquema de equilibrio general expuesto en la forma de un sistema de ecuaciones simultáneas; Jevons no lo hizo, y menos aún Menger, padre de una escuela de economistas que se niegan a emplear las matemáticas, la llamada escuela austríaca. El método matemático propugnado por Jevons y Walras acabó por imponerse cabalmente en la ciencia económica y hoy sólo cabe aplaudir la prognosis de Walras en esta irónica frase: «Je sais que beaucoup de personnes ont de la répugnance à apprendre les mathématiques, comme autrefois nombre de gens en avaient à monter en chemin de fer".

La postura política de Walras fue la del típico radical del siglo pasado, liberal y reformista. Recibió, a este respecto, una importante influencia de su padre, que fue un anticlerical, partidario de reformas fiscales progresivas y de nacionalizar la tierra. Walras hijo continuó la tradición reformadora, si bien visto desde hoy su romántico socialismo «sintético» —o synthetismeno puede sino suscitar una sonrisa: Segura nos explica muy bien la suavidad de las propuestas de un Walras que - al rechazar la revolución violenta, proponer no la confiscación, sino la adquisición de las tierras y apoyar entusiastamente a las cooperativas- está sin duda mucho más cerca de John Stuart Mill que de Karl Marx.

En su actitud reformista y su visión global de los problemas económicos, Walras siguió fielmente los pasos de su padre, que en 1831 había proclamado la necesidad de «réconcilier la morale avec l'économie politique, la théorie de la valeur avec les sentiments de la philanthropie».

\section{Un economista para economistas}

Una de las ideas centrales de Segura es que Walras fue un economista poco influyente en su época, lo que explica por sus problemáticas relaciones con muchos economistas, su aislamiento y su posición política. Es una opinión correcta, aunque matizable. La escasa influencia en vida de Walras resalta 
por el contraste entre lo que ocurrió antes y después de su muerte. Tras su fallecimiento hubo una explosión walrasiana que todavía dura, y a los estudios teóricos sobre equilibrio general -que los economistas pudieron acometer sin tomar contacto directo con los Elementos, dadas las obras de Cassel, Hicks y otros - se unió la erudita traducción inglesa de la obra realizada por el gran especialista William Jaffé y que fue saludada con júbilo en los más prestigiosos journals de la economía académica. Hay un solo economista contemporáneo de Walras con un ascendiente similar hoy en la profesión y ése es Marshall, que, como se ve en el apéndice matemático de sus Principios, era plenamente consciente del equilibrio general, aunque prefirió dirigir sus pasos hacia el equilibrio parcial.

Pero ello es posterior a la muerte de Walras. Lo que ocurrió antes es distinto en el sentido de que la obra teórica de Walras no tuvo gran impacto y difusión, pero sí fue conocida por muchos economistas. Independientemente de consideraciones $\mathrm{y}$ aprecios personales, Walras mantuvo contactos de diversa intensidad con: Barone, Böhm-Bawerk, Bortkiewicz, Edgeworth, Einaudi, Fisher, Foxwell, Gide, Jevons, Marshall, Menger, Pantaleoni, Pareto, Wicksell, Wicksteed y Wieser. No está nada mal para un economista aislado y poco influyente. Es verdad que aparte de que frecuentemente fue el propio Walras el que buscó los contactos y no al revés, muchos economistas no le trataron bien, pero - sin que sea menester hablar de la ideología- en esto de la naturaleza humana Walras tampoco era manco (Jaffé lo pinta hipocondríaco y de temperamento paranoico; Segura es parco al respecto), tal como testimonia un artículo de D. Walker traducido por quien esto escribe y publicado en Cuadernos Económicos de ICE en 1985.

Es correcto afirmar que Walras fue un economista para economistas y que no se le hizo suficiente justicia en vida - su relevancia para la crema de la profesión quedó de manifiesto con ocasión de su Jubileo en 1909-, pero quizá deba matizarse su calificación como poco influyente en su época. Sin salirnos del ámbito del marginalismo, habría que recordar a un Jevons acogido primero con suma frialdad por la Asociación Británica y eclipsado tras su muerte por Marshall. La economía, al igual que todas las demás ciencias, cuenta con casos en que considerables logros no tuvieron ningún reconocimiento en vida de sus autores, algo que Jevons y Walras sabían muy bien, puesto que ambos ayudàron a reivindicar para la teoría económica la olvidada aportación de H. H. Gossen.

\section{Walras en la bistoriografía económica}

Segura arremete contra los historiadores del pensamiento económico por haber escamoteado al Walras aplicado y social. Su embestida merece una 
réplica porque no resulta patente que la historiografía haya ignorado los aspectos no teóricos de Walras. En el Programa de Historia de las Doctrinas Económicas en la Complutense, en el que mucha responsabilidad ha tenido quien esto escribe, se indica a los alumnos que para el período posterior a 1870 es recomendable el manual de Hutchison (que no lleva una «n" después de la «i», pese a lo que Segura y muchos escriben, acaso en oblicuo recordatorio a la baronesa de Schlippenbach, que sí se apellida Hutchinson), el mismo que Segura elogia como el que más cabalmente refleja a Walras.

Es verdad que la teoría económica no es siempre totalmente independiente de las circunstancias en las que surge (esto es muy claro en teoría monetaria), pero me da la impresión que Segura asigna a veces excesiva importancia explicativa a dichas circunstancias. En realidad cuanto mejor teórico es un economista, menos necesitaremos del famoso «contexto», y Segura exagera al sostener que es necesario saber de los cercados británicos para comprender la teoría ricardiana. Las circunstancias de los autores pueden dar cuenta de sus preocupaciones, el origen de los problemas que se plantearon y la difusión de las teorías que elaboraron. Para seguir con Ricardo, son mucho más importantes las Leyes cerealeras que los cercados. Por eso es que dichas circunstancias son sin duda interesantes y los profesores de historia de la ciencia económica habitualmente asignamos en nuestras lecciones una sección de información al respecto y apreciamos mucho las biografías intelectuales (un ejemplo reciente y notable es el libro de Murphy sobre Cantillon). Pero salvo que uno entienda vagamente pensamiento o doctrinas económicas como meras opiniones o ideas generales, la importancia del contexto personal para el análisis puro es -al revés de lo que pensaba Marx- poco significante. Mis héroes son teoremas y no personas - sentenció Schumpeter-, aunque no fuera él precisamente un modelo de dicho apotegma.

El historiador que en el siglo xxI acometa la labor de explicar las contribuciones de la ciencia económica en la España de la segunda mitad del siglo actual deberá ir primero y fundamentalmente a los textos y ver qué aportaron los economistas del período. Puede que averigüe que Segura fue comunista, Schwartz liberal y ambos catedráticos al igual que decenas de otros. Pero creo que para su trabajo académico como historiador de la ciencia económica, esos datos serán apenas más importantes que si se enterase, por ejemplo, que Rojo, Sardá y el propio Segura fueron fumadores, Castañeda fue sordo, Lluch ministro, Boyer popular, Borrell menos, Carande longevo, Tamames ecologista, Beltrán católico, Rendueles banquero, Tedde poeta y Sampedro novelista.

Puede incluso que el averiguar detalles del «contexto» no estrictamente científico resulte perjudicial, porque a veces suscita en el investigador un 
sentimiento que le ofusca. Así le ocurre a ${ }^{*}$ Segura, que claramente experimenta simpatía por Walras y antipatía por Pareto y proporciona detalles de poco elegantes comentarios y maniobras a cargo de don Vilfredo: no hay nada, en cambio, de los desagradables párrafos que el «progresista» y «abierto» francés desgrana sobre el «filofascista» y «autoritario» italiano (los calificativos entre comillas son de Segura). A lo mejor es pedir peras al olmo, árbol sordo donde los haya, pero sería estupendo que nuestras filias y fobias no se notaran demasiado. Volveré sobre esto en la sección siguiente.

Sostiene Segura: «Jevons fue ricardiano en todo, excepto en la teoría del intercambio puro de mercancías», diagnóstico que rechazo de plano hasta que me aclare qué dosis de ricardianismo hay por ejemplo en la teoría del mercado de trabajo de un Jevons que, por cierto, dejó escrito su rechazo a "the noxious influence of authority». En cuanto al reproche de Segura a Marshall "por defender en forma simultánea la teoría del valor basado en la utilidad y la determinación del precio de los productos por los costes de producción», si es una alusión a la venerable disputa del equilibrio general versus parcial, es excesivamente sintética. Aunque se juzgue obvio que Marshall es una mente inope y el equilibrio parcial una extravagancia para analfabetos, habría sido preferible comentar siquiera brevemente las razones por las cuales -como dice Schumpeter- está tan extendido el empleo del equilibrio parcial por parte de los economistas, pese a la oposición de los teóricos «of the sterner type».

\section{Schumpeter $y$ otros}

En cuanto al reproche principal que formula Segura, hay que insistir en que la historia del pensamiento económico rinde cuenta del Walras no teórico. Más aún, varios historiadores aprecian los trabajos empíricos y sociopolíticos de Walras y los vinculan a su pensamiento teórico, es decir, exactamente lo que Segura dice que no ha ocurrido. Un ejemplo ilustre es el de Schumpeter, autor vilipendiado primero por Jaffé y después por Segura, pero que en Diez grandes economistas reconoce explicitamente el papel que la ideología de Walras pudo cumplir en la difusión de su obra; llega a decir que lo asombroso no es lo poco, sino lo mucho que se conoció a Walras. Destaca la importancia de los tres volúmenes walrasianos, pero subraya que su aportación a la teoría pura es lo más relevante: «Es indudable que su idea fundamental [el equilibrio general] le condujo a muchos resultados de importancia práctica. Así, por ejemplo, nadie ha defendido tan convincentemente como él la nacionalización de la tierra, y pocas contribuciones pueden compararse a la suya en el campo de la política monetaria. Pero todo esto nada 
significa al lado del conocimiento teórico que nos ha proporcionado.» Dirá también en la History que parte de los Estudios de Walras es de «una importancia de primer orden». No es acertado sostener, entonces, como hace Segura, que para Schumpeter todo el Walras, aparte los Elementos, era «literatura de tercera fila».

Con respecto a la evaluación de Segura del asimétrico tratamiento schumpeteriano de Walras-Gossen-Pareto, es un disparate afirmar que Gossen es "profusamente citado" en la History. De hecho, lo es llamativamente poco; generalmente junto a otros, no hay ninguna referencia biográfica en texto ni en notas y el lector no se entera en parte alguna de qué cosa escribió Gossen; el Entwicklung, por supuesto, no aparece en la List of books frequently quoted, en la que por cierto figuran los Eléments y los dos volúmenes de los Etudes. También son escasísimas las referencias a Gossen en Diez grandes economistas, en los Ensayos y en Sintesis de la evolución de la ciencia económica y sus métodos, en donde el Entwicklung aparece citado con el título incompleto y una fecha de publicación equivocada.

La actitud de Segura a propósito de Pareto ha sido ya mencionada, pero igual hay que dedicar unas líneas sobre el fascismo de Pareto y su designación como senador por Mussolini. Moriré feliz el día en que quienes crucifican a Pareto aclaren que Mussolini da su golpe militar en octubre de 1922 y Pareto muere en agosto de 1923. Terminemos ya con esto de hacer pasar a Pareto como un militante de-los camisas negras o de cualquier ideología cuando en realidad lo fue de la independencia intelectual, como apunta Hutchison. Pietri-Tonelli escribe en el apogeo del fascio, y aunque naturalmente no deja de destacar la cercanía de Pareto a dicha ideología, no para mientes en afirmar «che si vi fu movimento politico-economico, che rispondesse alle inclinazioni di Pareto, fu quello liberistico".

El retrato que dibuja Segura al glosar a Schumpeter a propósito de Walras y Pareto está gravemente distorsionado. Que Pareto reciba en Diez grandes economistas 39 páginas y Walras ocho no significa nada. Segura hurta al lector el dato fundamental de que esa obra no es un libro, sino una colección de escritos de tiempos y circunstancias muy diversos. Las páginas dedicadas a Walras corresponden a una nota necrológica publicada en una revista alemana en 1910; el de Pareto es un artículo conmemorativo de su centenario, publicado en inglés casi cuarenta años más tarde. El tratar a ambos textos como si fueran dos capítulos de un mismo libro roza el absurdo. Segura, que olvida que Schumpeter reprocha en la History y los Ensayos a Pareto su falta de generosidad hacia Walras, ironiza sobre la omisión en la History de la designación de Pareto como senador mussoliniano, pero no dice que en Diez grandes economistas Schumpeter comenta el episodio, apunta el hecho de las distintas ideologías de Walras y su sucesor, 
y aclara que Pareto jamás abrazó entusiastamente al fascismo (ni a ningún «ismo») y que hasta el fin de sus días predicó la moderación y la libertad de prensa y cátedra; no fue simplemente liberal en economía, como sugiere Segura en una nota al pie. Por último, en la extensa cita de la History a propósito de Pareto, Segura elude el contexto y no informa que el objetivo de Schumpeter era corregir a quienes veían en el italiano a un «uncritical liberal in the laissez-faire sense». (Anoto al margen que Segura cita incorrectamente a Diez grandes economistas: «burgués» en lugar de «pequeño burgués».)

Con respecto a otros historiadores criticados por Segura, puede apuntarse que en el referido Programa de mi asignatura en la Complutense no se hallará referencia alguna al libro de Barber, según Segura muy utilizado en la docencia; en la «tradición oral» de nuestra asignatura Barber ha sido crecientemente desaconsejado (creo que su popularidad se ha fundado esencialmente en su brevedad) y también se ha señalado que el libro de Blaug, un buen libro, brilla en los clásicos, Marx, los austríacos y Wicksell, pero no en Keynes, Walras y Marshall. Recomendamos, sí, el texto de Spiegel, que no ignora al Walras reformador.

No coincido con Segura en su despiadada desvalorización del Blaug que, por cierto, en sus notas bibliográficas recuerda la importancia asignada por Walras a sus escritos sobre economía aplicada, aunque ello pueda «sorprender a muchos lectores». Segura debería haber utilizado las ediciones más modernas del Blaug, en las que el capítulo sobre Walras ha sido modificado y mejorado y haber notado, antes de censurar al autor por la ausencia de una «Guía del lector» de Walras que, incluso en la primera edición, una "Guía» de los Elementos resultaba para Blaug esencial; si no la incorpora a su texto es porque Jaffé ya la ha concretado en los extensos comentarios a su traducción. El lector de Segura tendrá la impresión de que las páginas dedicadas a Walras por Blaug son mera «arrogancia ignorante», lo que es exagerado incluso aunque se admitan las correcciones de Segura, muy interesantes pero no totalmente admisibles. Es el propio Blaug el que recomienda se lean las páginas de Jaffé que cita Segura al respecto de la competencia y la máxima satisfacción. Segura parece opinar que Blaug sitúa el énfasis en la cuestión del número de ecuaciones e incógnitas; dice Blaug (como Schumpeter): «Resulta injustificada la opinión popular de que Walras contaba únicamente las ecuaciones y las incógnitas para demostrar la existencia de un equilibrio de mercado general.» $Y$ esto en la primera edición; en las posteriores Blaug define además correctamente al bien $\mathrm{E}$ como una renta perpetua. 
Reduccionismo no, énfasis si

Está en todo caso claro que los economistas han puesto especial énfasis en un aspecto de Walras, que todos coinciden - Walras incluido- en distinguir como su aportación fundamental: el equilibrio general. Claro que realizó Walras otros trabajos; ellos son conocidos pero considerados menos importantes. Lo mismo podría decirse de los textos de Jevons proponiendo diversas instancias de aconsejable intervención estatal en la economía; son interesante, pero en el ranking de sus méritos nunca ocuparán una posición elevada.

(Permítaseme interpolar una experiencia personal. La economía es una ciencia joven, pero a pesar de ello es imposible para una persona conocerla por completo; quizá Schumpeter fue el último que se aproximó bastante a ese objetivo. Por lo tanto, incluso los historiadores del pensamiento economico debemos apoyarnos en especialistas. No hay forma de que conozcamos toda nuestra asignatura de primera mano en fuentes originales. Por eso es que, guiado por el criterio de los historiadores, que tan acerbamente califica Segura, yo jamás había leído los Estudios de Walras. Cuando decidí escribir estas líneas seguí el consejo de Segura y los leí. Me agradó comprobar que mis maestros son confiables: todos aquellos historiadores del pensamiento económico no interesados especialmente en Walras pueden seguir yendo con la cabeza erguida si conocen sólo el corazón de los Elementos y han leído el capítulo correspondiente del Hutchison. Segura tiene razón en que los especialistas en Walras no pueden ignorar al Walras práctico, pero yerra al atribuir a los historiadores del pensamiento un mutismo generalizado al respecto.)

Dicho de otra forma, lo que unifica por ejemplo a Walras y Stuart Mill en la historia de la economía no es que ambos hayan sido reformadores progresistas, que lo fueron, sino su sobresaliente papel en la formación de esa ciencia. Si se exagera el papel de las propuestas nacionalizadoras de la propiedad de la tierra de Walras se puede terminar por colocarlo junto a la pléyade de economistas menores que plantearon estrategias parecidas. Se puede concebir una buena historia de la teoría económica que no contenga una sola referencia a Henry George o a Achille Loria, pero ella sería impensable sin Walras. (Entre paréntesis señalo un divertido error de Segura cuando menciona a Lloyd George y no a Henry George; parece claro que la cercanía con Walras se establece muchísimo más con el single tax del economista norteamericano que con el People's Budget del político británico que Keynes apoyará más tarde.)

Los economistas hispanohablantes agradeceremos mucho a Julio Segura 
si en el futuro nos sorprende con la traducción de los Estudios de Walras. Pero también aplaudimos el que haya empezado por los Elementos.

\section{Walrasianos y walrasistas}

Hay una variante inexplorada del izquierdismo de Walras que le permitirá compartir con otros conspicuos economistas la distinción entre el magister y los discípulos, tal como es moneda corriente en Marx o Keynes, para poner los ejemplos más conocidos. Esta variante pasa por la filiación entre el equilibrio general walrasista (horrible neologismo que acuño para distinguirlo de lo estrictamente original de Walras o walrasiano) y el socialismo. Son dos las perspectivas a través de las cuales dicha filiación puede manifestarse. En primer lugar, la aproximación existente entre un sistema walrasista en equilibrio (con desdibujado papel empresarial) y un sistema de economía planificada. En segundo lugar, desde otro punto de vista, el modelo walrasista puede interpretarse como una demostración abstracta de que "el mercado funciona»; como es fácil comprobar que la realidad se parece poco al modelo, éste puede derivarse en una confutación de la utilidad de la economía de mercado. Así, dice Segura en un artículo de Información Comercial Española de 1975 que el mercado es eficiente pero cuando existe, por lo que es de «vital importancia» determinar los casos en que no funciona. Destaco el que cite allí al Coase de 1960 y no al de 1937 sobre la empresa, a la cual explica precisamente por los costes que entraña el mecanismo del mercado.

Esta aproximación permitiría comprender la gran cantidad de economistas de izquierda a quienes actualmente atrae sobremanera lo walrasista y walrasiano. Un ejemplo notable es precisamente el propio Julio Segura y resulta llamativo que, pese a que reivindica la coherencia del Walras izquierdista y el teórico, se haya limitado a buscar al Walras rouge en lo walrasiano y no en lo walrasista. Debería completar ahora el círculo que parte de la romántica actitud liberal-socialista de Walras y culmina en la economía planificada. (A propósito de reduccionismo, sería ilustrativo que Segura indicase de qué lado está en la polémica que entablaron Jaffé y Morichima en el Journal of Economic Literature.)

Es muy posible que todo esto disgustaría profundamente a Léon Walras si lo viese hoy, pero al hilo de las reflexiones de Segura en la última parte de su artículo en Revista de Historia Económica podemos preguntarnos sobre la responsabilidad de Walras al respecto. ¿Diría legítimamente Walras que no es walrasista, igual que Marx afirmó que no era marxista?

Por un lado, su postura frente al socialismo es clara: «le dogmatisme est 
sa méthode scientifique, le despotisme est son procédé politique». Por otro lado, estigmatizó (al igual que buena parte de los economistas de antes, entonces y después) a los liberales extremos —recuérdese que la tradición liberal fue acaso más cruda en Francia que en cualquier otra parte- y a los que reducían toda la ciencia económica a dos palabras: laisser faire.

El proceder de Walras fue demostrar que el libre mercado «consigue la utilidad máxima», como evoca reprobador Wicksell en sus Lectures (Cournot también pensaba que el modelo walrasiano conducía a la exacerbación del laissez faire). De paso, creo que Segura exagera el liberalismo de Walras al sostener que se opuso al monopolio de emisión de billetes de Banco; tengo para mí que se opuso en realidad a dicha emisión. En la Théorie mathématique du billet de banque coquetea con una idea de emisión libre, pero con una impresionante reserva de activos financieros de respaldo: "pour une somme au moins égale à celle des billets émis» (mi subrayado), y termina insistiendo en que los inconvenientes de esos billetes son superiores a sus ventajas. En el Esquisse d'une doctrine économique et sociale repite esos argumentos y concluye: "ces opérations ne doivent pas se faire».

Pero Walras es walrasista en un sentido crucial. Creyó, optimista, que «la teoría pura es la luz de la teoría aplicada» y que la sola edificación teórica del sistema de equilibrio general le permitiría superar las «luchas interminables y fastidiosas" entre socialistas y liberales, al proporcionarle un criterio tajante de cuándo intervenir y cuándo no. Segura abre más puertas de las que cierra cuando sostiene que allí estriba la coherencia entre el Walras teórico y el práctico, puesto que en cuanto el mercado no funciona según el modelo, ello autoriza la intervención estatal.

Ante todo, no me parece del todo correcto sostener que Walras propone «políticas no competitivas» cuando la práctica demuestra que las condiciones teóricas óptimas no se cumplen. Lo que Walras procuraba es intervenir para lograr que el mercado funcione: «laisser faire ne doit pas signifier ne rien faire, mais laisser agir la libre concurrence» (subrayado de Walras).

Pero lo más grave es, puestos a ponderar al Walras práctico, eludir la denuncia de su debilidad fundamental. Walras era un iluso al creer que era tan sencillo «salir por fin de las doctrinas y entrar en la ciencia». No hay tal regla simple para saltarse a la torera las polémicas «interminables y fas. tidiosas» de estatistas y antiestatistas, como testimonia la copiosa bibliografía sobre economía del bienestar. Hay que señalar el optimismo radical de Walras, que se manifiesta también cuando esquiva los costes de la acción pública y defiende la intervención con el ingenuo y popular argumento de otro Estado, no el actual. Cuando oye a los críticos del Estado dice que está «d'accord avec eux s'il s'agit de l'Etat présent, mais non plus s'il s'agit de l'Etat futur». 
No hay que ser un experto en welfare economics ni en public choice para comprender que el «socialismo sintético» de Walras hace agua por los cuatro costados y que Segura le otorga más coherencia de la que tiene. Para muestra véase este párrafo de Walras - me permitiré llamarlo Manifiesto Walrasiano Walrasista - que revela la endeblez de su aparentemente sencillo criterio agenda-non agenda, como diría Bentham: «J'abandonnerais à l'Etat la production exclusive des services publics, et j'appellerais son intervention pour exercer ou pour constituer les monopoles naturels et nécessaires sur le pied de l'explotation dans l'interêt public, c'est-à-dire de la vente des produits au prix de revient et non au prix de bénefice maximum; mais je réclamerais pour l'initiative individuelle toutes les enterprises où la libre concurrence indéfinie ne rencontre pas d'obstacles». Nos ahogaríamos todos en la tinta que han hecho correr criterios como éstos, desde la definición de «servicio público» en adelante. Ser coherente al intentar enlazar la teoría abstracta con la práctica reformista, como hizo Walras y hacen Segura y los walrasistas, es una cosa. Acertar, otra.

\section{La calidad de la traducción}

No me atrevo por ahora a decir más que la traducción parece cuidada, lo que en el deletéreo panorama de las letras económicas hispanas es un considerable elogio. Lo que me llama la atención es que la traducción de Segura ha sido calificada con grandes aspavientos como extraordinaria por ilustres profesores que no pueden haber tenido tiempo (o como se dice a veces en hermosa expresión: tiempo material) de completar la labor a tres bandas que tal juicio requiere para ser digno de algún respeto. Son, en efecto, al menos tres volúmenes los que hay que leer y cotejar en este caso: la edición castellana, el original francés y la traducción inglesa de Jaffé justamente famosa y cuyas notas Julio Segura ha hecho muy bien en incorporar a su edición. La broma resulta en unas dos mil páginas con bastantes ecuaciones (lo de menos si el lector posee una mínima base matemática) y una redacción con frecuencia difícil; las otras obras de Walras tienen un estilo algo mejor, con lo que le ocurre lo mismo que a Keynes, cuyo libro más importante es con diferencia el peor escrito. $\mathrm{O}$ sea, hay que pelarse codos y cejas antes de emitir opinión fundada sobre esta traducción. Lo estoy haciendo ahora, pero si el lector está interesado en conocer la calidad de esta traducción castellana y no desea encargarse él mismo de la labor, advierto que ceteris paribus no me comprometo a nada antes de 1990.

Termino reiterando la bienvenida a Walras al mundo castellano y a Segura a la escuálida cofradía española de los economistas profesionales de 
la historia de su ciencia. Son conocidos los reproches de Samuelson a esta cofradia, a quien acusó con razón de tener por regla general una endeble base teórica. Por lo tanto, estaremos en condiciones de aumentar nuestros conocimientos de la mano de Julio Segura. Espero que no resulte un bappy end demasiado meloso y narcisista si digo que confío en que a veces también ocurra lo inverso. 